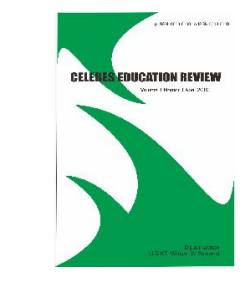

Celebes Education Review

http://journal.lldikti9.id/CER/index

Vol 1, No, 2, Oktober 2019

p-ISSN: 2656-7385 dan e-ISSN: 2684-7124

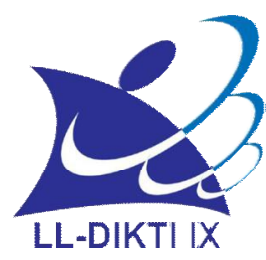

\title{
Perbandingan Keefektifan Cornell Notes Method Dan Mind Maps Ditinjau Dari Self Efficacy
}

\author{
${ }^{1}$ Nurul Iman \\ 1Bidang Pendidikan Matematika, STKIP YPUP Makassar \\ Email: nuruliman39@gmail.com
}

\section{Artikel info}

Artikel history:

Received; 25-07-2019

Revised:21-08-2019

Accepted;05-10-2019
Abstract: This study aims to examine the comparison of the effectiveness of note taking styles of students who use the cornell notes method and mind maps in terms of student self-efficacy. This type of research is a quasi-experimental study with a pretetsposttest nonequivalent comparison-group design. The population in this study were all eighth grade students of SMPN 1 Sungguminasa. The sample is class $\mathrm{VIII}_{\mathrm{E}}$ and $\mathrm{VIII}_{\mathrm{B}}$ as the experimental class. Class $\mathrm{VIII}_{\mathrm{E}}$ is treated in the form of a notetaking style using cornell notes, while class $\mathrm{VIII}_{\mathrm{B}}$ is treated as a note-taking style by mind maps. To test the effectiveness of learning using a paired sample $t$ test. To test the difference in effectiveness using the independent sample t-test. The results of this study are: 1) the cornell notes method is not effective if viewed from the students' self efficacy, 2) mind maps is effective if it is reviewed by students' self-efficacy. 3) There is a difference in effectiveness between the cornell notes method and mind maps in terms of students' self-efficacy where students who record by mind maps get better efficacy scores than students who record by cornell notes method.

Abstrak: Penelitian ini bertujuan untuk menguji perbandingan keefektifan gaya mencatat siswa yang menggunakan cornell notes method dan mind maps ditinjau dari self efficacy siswa. Jenis penelitian adalah penelitian quasi eksperimen dengan desain pretets-posttest nonequivalent comparison-group design. Populasi dalam penelitian ini adalah seluruh siswa kelas VIII SMP Negeri 1 Sungguminasa. Sampelnya yaitu kelas VIII $I_{E}$ dan VIII $I_{B}$ sebagai kelas eksperimen. Kelas $\mathrm{VIII}_{\mathrm{E}}$ diberi perlakuan berupa gaya mencatat dengan cara cornell notes, sedangkan kelas $\mathrm{VIII}_{B}$ diberi perlakuan berupa gaya mencatat dengan cara mind maps. Untuk menguji keefektifan pembelajaran menggunakan uji paired sample $t$ test. Untuk menguji perbedaan keefektifan menggunakan uji independent sample t-test. Adapun hasil penelitian ini adalah: 1) cornell notes method tidak efektif jika ditinjau dari self efficacy 
siswa, 2) mind maps efektif jika ditinjau self-efficacy siswa. 3) Terdapat perbedaan keefektifan antara cornell notes method dan mind maps ditinjau dari self-efficacy siswa dimana siswa yang mencatat dengan cara mind maps mendapat skor selff efficacy yang lebih baik dari pada siswa yang mencatat dengan cara cornell notes.

\section{Keywords:}

cornell notes method, mind maps, dan selfefficacy
Coresponden author:

Email: xxxx@gmail.com

artikel dengan akses terbuka dibawah lisensi CC BY -4.0

\section{Pendahualuan}

Matematika merupakan salah satu mata pelajaran yang wajib dipelajari di setiap jenjang pendidikan di Indonesia, mulai dari tingkat SD, SMP, SMA/SMK, bahkan di beberapa prodi perguruan tinggi. Seiring dengan perkembangan zaman menuntut adanya upaya peningkatan mutu pendidikan di Indonesia, upaya tersebut harus dilakukan secara menyeluruh. Demi mewujudkan peningkatan tersebut, Kementrian Pendidikan dan Kebudayaan (Kemendikbud) melakukan penyempurnaan kurikulum. Kurikulum terbaru yang dikenalkan pada dunia pendidikan di Indonesia setelah Kurikulum Tingkat Satuan Pendidikan (KTSP) adalah kurikulum 2013. Berbagai undang-undang dan peraturan tentang pendidikan diamandemen menyesuaikan dengan kurikulum 2013

Selanjutnya dalam Permendikbud No. 65 Tahun 2013 disebutkan bahwa proses pembelajaran mengalami perubahan dari siswa diberi tahu menjadi siswa mencari tahu, dari guru sebagai satu-satunya sumber belajar menjadi belajar berbasis aneka sumber belajar, selanjutnya dari pendekatan tekstual menuju proses sebagai penguatan penggunaan pendekatan ilmiah (Permendikbud Nomor 65 Tahun 2013, 2013, p.1). Dari permendikbud tersebut disebutkan bahwa pembelajaran seharusnya menggunakan proses ilmiah. Oleh karena itu kurikulum 2013 mengamanatkan esensi pendekatan ilmiah/saintifik dalam proses pembelajarannya. Proses pembelajaran dengan pendekatan saintifik diyakini oleh pengembang kurikulum dapat mengembangkan sikap, keterampilan, dan pengetahuan peserta didik dalam proses kerja yang memenuhi kriteria ilmiah. Atas dasar hal tersebut dalam penelitian ini akan menggunakan pembelajaran yang berbasis saintifik dalam proses pembelajaran di kelas.

Di dalam Kurikulum 2013 diharapkan pembelajaran lebih berorientasi pada siswa (student centered), agar hal tersebut dapat tercapai maka menurut Marsigit (2015, p.2), peran guru tidak lagi sebagai pentransfer ilmu, melainkan sebagai fasilitator atau membantu siswa agar siswa mampu menguasai berbagai kompetensi yang diharapkan. Oleh karena itu, kegiatan pembelajaran yang diselenggarakan diharap mampu mengembangkan kemampuan untuk mengetahui, memahami, melakukan sesuatu, hidup dalam kebersamaan, dan mengaktualisasikan diri. Dengan perkataan lain, kegiatan pembelajaran perlu menggunakan prinsip yang: (1) berpusat pada peserta didik, (2) mengembangkan kreativitas peserta didik, (3) menciptakan kondisi menyenangkan dan menantang, (4) bermuatan nilai, etika, estetika, logika, dan kinestetika, dan (5) menyediakan pengalaman belajar yang beragam

Pendekatan saintifik merupakan suatu pendekatan dimana di dalamnya harus memuat kejadian yang telah terjadi dalam kehidupan sehari-hari. Hal tersebut disebutkan oleh Cuff \& Payne (Cohen, 2007, pp.15 -16), "As Cuff and Payne (1979) say: 'A scientific approach necessarily involves standards and procedures for demonstrating the "empirical warrant" of its findings, 
showing the match or fit between its statements and what is happening or has happened in the world" yang berarti, pendekatan ilmiah harus melibatkan standar dan prosedur untuk menunjukkan' 'bukti empiris' 'temuannya, menunjukkan pertandingan atau kesesuaian antara pernyataan dan apa yang terjadi atau telah terjadi di dunia.

Pembelajaran ilmiah harus berdasarkan bukti-bukti dari objek yang dapat diamati, empiris dan terukur dengan prinsip penalaran yang spesifik. Selain itu dengan kriteria tersebut, pembelajaran ilmiah juga memandirikan siswa dan melibatkan langsung siswa dalam pembelajarannya. Adapun langkah-langkah pembelajaran berbasis saintifik (Permendikbud no 81A Tahun 2013, 2013, p.4) adalah sebagai berikut : (1) Mengamati, yaitu dengan indra (membaca, mendengar, menyimak, melihat, menonton, dan sebagainya) dengan atau tanpa alat. (2) Menanya, yaitu membuat dan mengajukan pertanyaan, tanya jawab, berdiskusi tentang informasi yang belum dipahami, informasi tambahan yang ingin diketahui, atau sebagai klarifikasi. (3) mengumpulkan informasi, yaitu mengeksplorasi, yaitu mencoba, berdiskusi, mendemonstrasikan, meniru bentuk/gerak, melakukan eksperimen, membaca sumber lain selain buku teks, mengumpulkan data dari narasumber melalui angket, wawancara, dan memodifikasi/ menambah/ mengembangkan. (4) Mengasosiasi, yaitu Mengolah informasi yang sudah dikumpulkan, menganalisis data dalam bentuk membuat kategori, mengasosiasi atau menghubungkan fenomena/informasi yang terkait dalam rangka menemukan suatu pola, dan menyimpulkan. (5) Mengomunikasikan, yaitu menyajikan laporan dalam bentuk bagan, diagram, atau grafik; menyusun laporan tertulis; dan menyajikan laporan meliputi proses, hasil, dan kesimpulan secara lisan

Melalui metode pembelajaran berbasis saintifik, diharapkan prestasi belajar siswa dapat meningkat seiring dengan lebih aktifnya siswa di dalam kegiatan pembelajaran. Hal tersebut didukung oleh penelitian yang dilakukan oleh Untayana \& Harta (2016, p.1) yang menyatakan bahwa pendekatan saintifik efektif dalam meningkatkan prestasi belajar dan komunikasi matematis siswa. Untuk mendukung metode pembelajaran saintifik maka siswa dalam setiap tahapan pembelajaran harus mampu mendokumentasikan pelajaran dengan baik dan terorganisir. Adapun cara agar siswa dapat mendokumentasikan pelajaran dengan baik dan terorganisir adalah membuat catatan ringkasan materi.

Pada awal pembelajaran, seorang guru dapat mengajarkan terlebih dahulu cara mendokumentasikan pelajaran agar baik dan terorganisir. Adapun gaya dalam membuat catatan ringkasan materi tersebut dapat berupa linear note taking style dan non linear note taking style. Mengajarkan cara mendokumentasikan tersebut dibutuhkan karena masih banyak siswa yang belum memiliki kemampuan dalam mengorganisir catatan, bagaimana cara merangkum poinpoin utama dari suatu materi, sehingga catatan yang siswa buat menjadi kurang efektif, hal itu menyebabkan siswa kesulitan dalam melakukan review materi yang telah lalu ketika menjelang ujian.

Sejalan dengan hal di atas, siswa yang aktif dalam mencatat akan mempunyai prestasi yang lebih baik dibandingkan siswa yang tidak melakukan pencatatan. Hal tersebut diungkapkan oleh Tsai-Fu (2009, p.16) yang menyatakan bahwa siswa yang aktif dalam melakukan pencatatan selama memiliki prestasi yang lebih baik dari pada yang pasif dalam mencatat. Kiewra (2002, p.72) juga menyatakan bahwa students are right to record notes and value note taking. There is strong evidence that recording lecture notes leads to higher achievement than not recording notes, whether the notes are reviewed or not.

Bagi dunia keilmuan, matematika berperan sebagai bahasa simbolik yang memungkinkan terwujudnya komunikasi yang cermat dan tepat. Matematika bukan saja menyampaikan informasi secara jelas dan tepat, tetapi juga singkat. Suatu rumus jika ditulis dengan bahasa verbal memerlukan kalimat yang sangat banyak, sehingga peluang untuk 
terjadinya salah informasi dan salah interpretasi juga semakin besar, dalam bahasa matematika cukup ditulis dengan model yang sederhana sekali (Sumantri, 1994, p.203). Oleh karena itu dalam proses pembelajaran matematika dibutuhkan gaya mencatat (note taking style) yang akan menghasilkan suatu catatan dapat dengan mudah dimengerti dan direview ketika kembali membuka catatan tersebut.

Sejalan dengan hal tersebut, menurut jurnal yang ditulis oleh Boch \& Piolat (2005, p.101) , yaitu Note-takers take notes to fulfill two major functions: to record information and/or to aid reflection, ... note-takers are striving to avoid forgetting something, yang berarti bahwa Membuat catatan memiliki dua fungsi utama : untuk merekam informasi dan / atau untuk membantu refleksi, ... membuat catatan merupakan suatu usaha untuk menghindari seseorang melupakan sesuatu.

Dalam membuat catatan tentunya dibutuhkan suatu gaya mencatat, terdapat dua gaya dalam mencatat yakni linear style dan non linear style sebagaimana disebutkan oleh Makany, Kemp \& Dror (2009, p.3). Contoh dari linear style adalah cornell notes dan point lingkaran traditional (Kaivola \& Lokki, 2010, p.460), sedangkan mind maps merupakan salah satu contoh dari gaya mencatat yang tidak berurutan (non linear note taking style).

Sejalan dengan itu, cornell notes juga dijelaskan oleh Burns \& Sanfield (2004, p.103) yang menyatakan bahwa Cornell University di Amerika Serikat menggunakan sebuah system catatan linear aktif dimana siswa menghubungkan catatan ke hal yang tujuannya spesifik, hasil dan kriteria penilaian. Dalam membuat cornell notes dilakukan dengan cara membuat garis pemisah tengah. Salah satu sisi halaman diberi label 'tujuan kursus dan tugas' dan yang lainnya diberi label 'catatan'.

Cornell Notes didesain oleh Walter Pauk dari Cornell University. Adapun cara membuat sistem pencatatan bergaya Cornell dijelaskan oleh Pauk (2011, p.244) sebagai berikut: Pertama, menggambar garis vertikal di sisi kiri dari setiap halaman dua setengah inci dari tepi kertas; maka kolom sebesar dua inci tersebut menciptakan kolom isyarat. Berikutnya, menggambar garis horizontal dua inci dari bagian bawah halaman. Pada bagian itu adalah batasan untuk wilayah ringkasan

Sedangkan mind maps dijelaskan oleh Greany \& Rodd (2003, p.68) yang menyatakan bahwa "(Mind Maps) helps us plan and remember things, (they) help me remember and it's easier to do than just writing things in list" yang berarti bahwa mind maps dapat membantu mengingat sesuatu lebih lama sehingga mampu meningkatkan daya ingat.

Mind maps, menurut Buzan (2006, p.135), adalah grafis, metode jaringan dari penyimpanan, mengorganisir dan memprioritaskan informasi (biasanya di atas kertas) menggunakan kunci atau memicu kata-kata dan gambar, yang masing-masing akan 'snap pada' kenangan khusus dan mendorong pikiran-pikiran baru dan ide. Adapun langkah membuat mind maps menurut Buzan (2012, p.15) adalah: (1) Mulailah dari bagian tengah kertas kosong yang sisi panjangnya di letakkan mendatar. Memulai menggambar dari tengah akan memberi keleluasaan bagi otak untuk berfikir memancar ke segala arah dan akan mengekspresikan diri lebih bebas dan alami. (2) Gunakan gambar atau foto untuk ide sentral, karena gambar melambangkan seribu kata dan dapat membantu kita menggunakan imajinasi. Selain itu gambar dapat memberi fokus perhatian dan menyenangkan bagi mata. (3) Gunakan warna pada mind maps, karena warna sama menariknya dengan gambar, selain itu warna dapat membuat mind map lebih cera dan hidup serta merangsang cara berpikir kreatif. (4) Hubungkan cabang-cabang utama ke gambar pusat dan hubungkan cabang- cabang tingkat dua dan tiga ke tingkat satu atau dua, dan seterusnya. Alasannya karena otak kita bekerja berdasarkan asosiasi dan jika cabang-cabang saling berkaitan di halaman kertas, maka setiap gagasan akan saling berkaitan. Kaitan ini juga menciptakan dan memelihara struktur dasar. (5) Buatlah garis hubung yang 
melengkung, alasannya karena otak jauh lebih tertarik pada garis lengkung seperti yang kita temukan di alam. (6) Gunakan kata kunci untuk setiap garis/cabang. (7) Gunakan gambar dan simbol diseluruh mind map, karena setiap gambar bermakna seribu kata, selain itu gambar dan simbol mudah diingat dan merangsang asosiasi-asosiasi baru dan kreatif.

Oleh karena itu dalam penelitian ini yang harus dilakukan oleh peneliti adalah mengajarkan gaya mencatat yang linear dan non linear sebelum dimulainya pemberian materi kepada siswa, agar ketika proses pembelajaran berlangsung dapat diterapkan langsung oleh siswa. Apapun gaya mencatat yang digunakan pada akhirnya juga bertujuan untuk meningkatkan prestasi belajar siswa.

Stiggins \& Cahppuis (2012, p.35) menyatakan tentang definisi prestasi yaitu "achievement or learning targets define academic succes-what we want students to know and be able to do". Artinya prestasi atau target belajar mendefinisikan keberhasilan akademis dari apa yang ia ketahui dan apa yang dapat mereka lakukan. Ditambah oleh Nitko \& Brookhart (2011, p.497) yang menyatakan bahwa "achievement is knowledge, skill, and abilities that students have developed as a result instruction". Hal tersebut bermakna bahwa prestasi adalah pengetahuan, keterampilan, dan kemampuan dari siswa yang telah berkembang sebagai hasil dari pembelajaran. Selain itu, Arends \& Kilcher (2010, p.59) menambahkan mengenai prestasi bahwa "achievement is satified when student strive to learn particular subjects or acquire difficult skills and are succesfull in their quest". Artinya prestasi merupakan kepuasan tersendiri bagi siswa ketika berhasil mempelajari mata pelajaran tertentu atau mendapatkan keterampilan dalam menyelesaikan sesuatu yang dirasa sulit dan akhirnya berhasil dalam usahanya.

Adapun untuk mengukur prestasi belajar dalam hal ini adalah menggunakan tes prestasi belajar sebagaimana diungkapkan Johnson \& Christensen (2012, p.153) menyatakan bahwa "achievement test are designed to measure the degree of learning that has taken place after a person has been exposed to a specific learning experience". Makna dari pernyataan ini adalah tes pestasi dirancang untuk mengukur tingkat pembelajaran yang telah berlangsung setelah seseorang telah terkena pengalaman belajar tertentu

Selain teknik mencatat dan ingatan, masih ada berbagai macam faktor yang dapat mempengaruhi hasil belajar, diantaranya adalah self-efficacy siswa terhadap pelajaran matematika

Masalah lain yang diduga erat kaitannya dengan prestasi belajar matematika yang rendah adalah rendahnya keyakinan siswa terhadap kemampuan diri sendiri, baik dalam belajar maupun menghadapi soal-soal atau masalah matematika. Bandura (1997, p.3) mengatakan bahwa keyakinan seseorang terhadap kemampuan mereka dalam mengatur dan menjalankan program tindakan yang diperlukan untuk menghasilkan pencapaian yang diberikan disebut self-efficacy

Pendapat yang sama juga diungkapkan oleh Santrock (2011, p. 473) yang menyebutkan "self efficacy is the belief that one can master a situation and procedure positive outcomes". Woolfolk (2007, p.392) "Self-efficacy is our belief about our personal competence or effectiveness in a given area and important variable for student to monitor. Secara umum, definisi di atas menjelaskan self-efficacy sebagai keyakinan yang mendorong atau mengarahkan seseorang untuk menemukan solusi dalam sebuah situasi dan mampu menghasilkan sikap positif dari situasi yang terjadi tersebut. Dengan kata lain self-efficacy menjadi kunci dan stimulus utama yang bisa membantu seseorang menemukan solusi atau jalan keluar dari sebuah situasi yang sedang dihadapi. Self-efficacy juga sangat berpengaruh terhadap motivasi dan prestasi seseorang dalam menyelesaikan tugas-tugasnya, sebagaimana diungkapkan oleh Pajares \& Urdan (2002, p.36). Selain itu self-efficacy juga dapat menjadi penilaian yang spesifik terhadap kemampuan seseorang dalam menjalankan tugasnya, sebagai mana disebutkan oleh Pajares \& Miller ( 1997, p. 213). kinerja Self-efficacy juga berkontribusi secara signifikan terhadap prestasi akademik siswa, (Ahmad \& Husain, 2012, p.13; Taat \& Rozario, 2014, p.41). Self- 
efficacy juga berasosiasi secara positif dengan prestasi belajar matematika siswa (Liu \& Koirala, 2006, p.10).

Selain itu Zimmerman, Bonner \& Kovach (1996, h.140) menyatakan bahwa "self-efficacy the degree to which a person feels capable of succesfully performanting acertain task, such as solving a type of science problem. Maksudnya self-efficacy merupakan suatu tingkat (kadar) yang menunjukkan perasaan seseorang untuk mampu dalam menyelesaikan tugas dengan berhasil, seperti memecahkan masalah dalam permasalahan ilmu pengetahuan.

Menurut Bandura (Maddux, 1995, p.9) Self-efficacy ditunjukkan dengan variasi tiga dimensi yaitu : (1) magnitude adalah dimensi yang berhubungan dengan tingkat kesulitan tugas. Orang yang memiliki self-efficacy tinggi cenderung akan memilih mengerjakan tugas-tugas yang sifatnya sulit dibandingkan yang sifatnya mudah; (2) Kekuatan (strenght) dari self-efficacy mengacu pada keyakinan seseorang mengenai kemampuan yang dimiliki. Hal ini berkaitan dengan ketahanan dan keuletan individu dalam pemenuhan tugasnya. (3) Generality menjelaskan keyakinan individu untuk menyelesaikan tugas-tugas tertentu dengan tuntas dan baik

\section{Metode Penelitian}

Penelitian ini menggunakan pendekatan kuantitatif. Adapun jenis penelitian ini adalah penelitian Eksperiman semu (Quasi Experiment). Variabel terikat dalam penelitian ini adalah prestasi belajar matematika, komunikasi matematis dan self-efficacy siswa dan variabel bebasnya adalah Metode Pembelajaran Matematika Berbasis Saintifik dengan Linear Note Taking Style Dan Non Linear Note Taking Style. Desain penelitian ini menggunakan desain pretest dan post-test. Pre-test untuk melihat kondisi awal siswa terhadap prestasi belajar, komunikasi matematis dan self-efficacy siswa sebelum diberikan perlakuan (threatment). Sedangkan Post-tes digunakan untuk melihat keefektifan pembelajaran prestasi belajar, komunikasi matematis dan self-efficacy siswa setelah diberikan perlakuan (threatment) berupa Metode Pembelajaran Matematika Berbasis Saintifik dengan Cornell Notes Method Dan Mind Maps

Penelitian ini akan dilaksanakan di SMP Negeri 1 Sungguminasa, dan waktu pelaksanaan penelitiannya akan dilaksanakan pada akhir Maret hingga awal Mei tahun 2019. Adapun SMP Negeri 1 Sungguminasa Ini Termasuk Dalam Klasifikasi B Untuk Mata Pelajaran Matematika Berdasarkan Laporan Hasil Ujian Nasional Dari Kemendikbud Tahun 2014.

Populasi Dalam Penelitian Ini Adalah Seluruh Siswa Kelas VIII SMP Negeri 1 Sungguminasa Tahun pelajaran 2018/2019. Teknik pengambilan sampel dalam penelitian ini adalah dengan menggunakan sistem random atau acak. Dari 10 kelas populasi yaitu $\mathrm{VIII}_{\mathrm{A}}, \mathrm{VIII}_{\mathrm{B}}$, $\mathrm{VIII}_{C}, \mathrm{VIII}_{\mathrm{D}}, \mathrm{VIII}_{\mathrm{E}}, \mathrm{VIII}_{\mathrm{F}}, \mathrm{VIII}_{\mathrm{G}}, \mathrm{VIII}_{\mathrm{H}}, \mathrm{VIII}_{\mathrm{I}}$, dan $\mathrm{VIII}_{\mathrm{J}}$, kemudian diambil dua kelas secara acak sehingga terpilihlah kelas $\mathrm{VIII}_{\mathrm{E}}$ dan $\mathrm{VIII}_{\mathrm{B}}$. Kemudian dari kedua kelas tersebut diacak kembali untuk menentukan kelas yang diberi Metode Pembelajaran Matematika Berbasis Saintifik dengan cara Cornell Notes sebagai kelompok eksperimen I dan kelas yang diberi Metode Pembelajaran Matematika Berbasis Saintifik dengan mind maps kelompok eksperimen II. Adapun kelas yang menjadi kelompok eksperimen I adalah kelas $\mathrm{VIII}_{\mathrm{E}}$ sedangkan kelas yang menjadi kelompok eksperimen II adalah kelas VIII . adapun jumlah siswa pada masing-masing kelas adalah 33 orang.

Desain yang digunakan pada penelitian ini adalah pretets - posttest nonequivalent comparison-group design. Kelompok yang akan digunakan dalam penelitian ini terdiri atas dua kelompok yang akan diberikan perlakuan berupa Metode Pembelajaran Matematika Berbasis Saintifik dengan cornell notes method Dan mind maps. 
Tahap-tahap yang dilakukan dalam pene-litian ini adalah menyusun instrumen penelitian (silabus, RPP, lembar kerja siswa, soal pretest dan posttest untuk masing-masing variabel, serta rubrik penskoran sesuai dengan variabel yang akan diteliti); memvalidasi instrumen penelitian dilakukan dengan judgment ahli; uji coba instru-men penelitian; melakukan prasurvey dan per izinan ke sekolah; memberikan pretest pada sampel penelitian; melakukan penelitian; mem-berikan posttest pada sampel penelitian

Teknik pengumpulan data yang dimaksud disini adalah tahapan yang dilalui dalam pengumpulan data. Adapun teknik pengumpulan data yang akan digunakan adalah dengan menggunakan instrumen tes dan non tes. Data yang digunakan merupakan data primer yang rencananya akan diperoleh langsung oleh peneliti yaitu dengan memberikan instrumen penilaian kepada kelas kontrol dan kelas eksperimen sebelum diberikan perlakuan maupun setelah diberikan perlakuan.

Instrumen non tes berupa angket/inventory diberikan dengan tujuan untuk mengukur self-efficacy siswa terhadap matematika. Berikut ini adalah tahapan-tahapan dalam pengumpulan data adalah sebagai berikut: (1) Menyusun instrumen penelitian; (2)Meminta beberapa dosen untuk memvalidasi instrumen penelitian; (3) Melaksanakan uji coba instrumen penelitian; (4) Mengestimasi reliabilitas instrumen penelitian; (5) Melakukan revisi instrumen penelitian; (6) Memberikan Pre tes kepada dua kelas eksperimen di masing-masing kelas; (7) Penelitian dilaksanakan bersama dengan guru-guru disekolah; (8) Memberikan posttest kepada sampel peneletian setelah dilakukan teratment. Instrumen non tes yang digunakan dalam penelitian ini adalah berupa angket. Angket self-efficacy siswa terhadap matematika terdiri dari 20 pernyataan, Model skala yang digunakan adalah skala Likert. Jawaban dari siswa terdiri dari 5 macam jawaban, yaitu selalu ( SL), sering (SR), kadang-kadang (KK), Jarang (JR)dan tidak pernah (TP) dengan pemberian skor berturut-turut jika pernyataannya positif 5,4,3,2,1, sedangkan jika pernyataannya negatif 1,2,3,4,5. Angket self-efficacy disususn berdasarkan kisikisi dari tinjauan teori.

Sebelum instrumen yang akan digunakan untuk mengukur prestasi belajar, komunikasi matematis dan self-efficacy diberikan kepada siswa, terlebih dahulu dilakuakan uji validitas terhadap instrumen tersebut, agar instrumen yang digunakan memiliki ketepatan dan mengukur apa yang seharusnya diukur. Untuk memperoleh bukti validitas instrumen digunakan dua cara, yaitu validitas isi (Content Validity) dan validitas konstruk (contruct validity). Teknik analisis data pada penelitian ini dilakukan dengan mendeskripsikan data yang diperoleh. Deskripsi data dilakukan dengan mencari nilai rata-rata, nilai maksimal, nilai minimal, standar deviasi dan ketuntasan dari data yang diperoleh, baik untuk data sebelum perlakuan, maupun untuk data setelah perlakuan.

Sebelum melakukan analisis, terlebih da-hulu dilakukan uji asumsi terhadap ketiga kelompok, baik sebelum maupun setelah perlaku-an. Uji normalitas multivariat dilakukan dengan menggunakan jarak Mahalanobis . Adapun kriteria keputusan yang digunakan adalah asum-si normalitas multivariat terpenuhi jika sekitar $50 \%$ data mempunyai nilai $d_{j}{ }^{2} \leq \chi_{(2 ; 0,5)}^{2}$.

Untuk mengetahui homogenitas matriks varian kovarian dilakukan uji Box's $M$, sedangkan untuk mengetahui homogenitas varian dilakukan uji homogenitas menggunakan Levene Test. Keputusan uji dan kesimpulan terhadap uji hipotesis dilakukan pada taraf signifikansi 0,05. Adapun kriteria keputusan yang digunakan adalah data dikatakan telah memenuhi uji asumsi homogenitas matriks varian kovarian dan homogenitas varian jika nilai signifikansinya lebih besar dari 0,05. 


\section{Hasil dan Pembahasan}

Data self-efficacy siswa ini diperoleh dengan memberikan tes angket sebanyak 22 item pada kedua kelompok baik sebelum treatment maupun sesudah treatment. Berdasarkan hasil analisis statistik deskriptif seperti yang disajikan pada tabel 9, maka nilai rata-rata self-efficacy pada kedua kelas eksperimen mengalami peningkatan, yaitu pada kelas eksperimen I yang diajar dengan metode saintifik yang disintesiskan dengan Cornell Notes, maka nilai rata-rata sebelum diberikan treatment adalah 69,55 dan setelah diberikan treatment adalah 70,27, dimana nilai minimum pretest adalah 62,00 dan nilai maksimumnya adalah 87,00 , sedangkan nilai minimum posttest adalah 60,00 dan nilai maksimumnya adalah 93,00. Pada kelas eksperimen II yang diajar dengan metode saintifik yang disintesiskan dengan Mind maps, maka nilai rata-rata sebelum diberikan treatment adalah 71,36 dan setelah diberikan treatment rat-ratanya meningkat menjadi 75,27, dimana nilai minimum pretest adalah 52,00 dan nilai maksimumnya adalah 87,00, sedangkan nilai minimum posttest adalah 64,00 dan nilai maksimumnya adalah 89,00. Hasil uji normalitas multivariat terlihat bahwa nilai Box's M sebesar 7,704 serta nilai signifikansi yang diperoleh lebih dari 0,05, yakni 0,293. Karena nilai signifikansi lebih besar dari 0,05 maka dapat disimpulkan data pretest berasal dari populasi yang mempunyai varians kovarians yang homogen (sama). Berdasarkan hasil perhitungan multivariate test diperoleh signifikansi untuk Hotelling's Trace Hotelling's Tracenya > 0,05 yaitu sebesar 0,083. Hal ini menunjukkan bahwa $\mathrm{H}_{\circ}$ diterima. Dengan demikian dapat disimpulkan bahwa kondisi awal sebelum treatment tidak terdapat perbedaan rata-rata prestasi belajar, komunikasi matematis, dan self-efficacy siswa antara kelompok CN dan MM.

Untuk nilai signifikansi pada variabel self-efficacy, dimana nilai sig (2-tailed) yang didapatkan adalah 0,001<0,05, dengan demikian $\mathrm{H}_{\mathrm{o}}$ ditolak, yang berarti bahwa rata-rata skor akhir self-efficacy siswa kelas eksperimen I dibandingkan kelas eksperimen II berbeda secara signifikan. Untuk mengetahui kelas mana yang lebih baik self-efficacy setelah treatment maka dapat dilihat dari rerata hasil posttest pada kedua kelas eksperimen tersebut. Pada kelas CN reratanya adalah 70,273 dan pada kelas MM adalah 75,273. Dari kedua rerata tersebut terlihat bahwa untuk self-efficacy siswa, kelas yang diberikan treatment MM lebih efektif dibandingkan kelas $\mathrm{CN}$.

Tidak meningkatnya self-efficacy tersebut dapat terlihat selama dilakukannya treatment pada kelas CN, yaitu banyaknya siswa yang mengeluh bosan harus mencatat materi yang cukup banyak selama proses pembelajaran berlangsung. Kebosanan inilah yang ditengarai oleh peneliti mempengaruhi self-efficacy siswa pada saat belajar matematika. Namun karakteristik Cornell Notes yang menuntut keterurutan pada saat mencatat materi berdampak besar pada prestasi belajar dan komunikasi matematis siswa. Hal tersebut dikarenakan karakteristik matematika itu sendiri dalam penyelesaian soal-soalnya membutuhkan keterurutan prosedur dalam penulisan jawabannya. Sehingga anak yang sering menggunakan Cornell Notes dalam proses belajar mengajarnya akan merasa terbantu dan lebih mudah dalam menyelesaiakan soal matematika yang membutuhkan keterurutan dalam penulisan jawabannya. Jadi gaya mencata Cornell notes ini mempunyai sisi positif dan juga negatif, positifnya adalah karakteristik Cornell Notes yang membutuhkan keterurutan dalam sistem pencatatanya akan membantu membiasakan siswa menjawab soal matematika yang jawabannya membutuhkan keterurutan prosedur pada saat menyelesaikan soal 
Namun siswa yang terbiasa membuat mind maps justru cenderung meningkat self efficacynya, karena siswa terbiasa berkreasi sendiri dalam membuat catatanya sehingga menumbuhkan rasa percaya diri dalam dirinyayang berimplikasi meningkatnya self-efficacy siswa selama proses pembelajaran.

\section{Simpulan dan Saran}

Berdasarkan pengujian hipotesis diperoleh kesimpulan bahwa: (1) Metode pembelajaran matematika berbasis saintifik dengan menggunakan cornell notes method tidak efektif jika ditinjau dari self-efficacy siswa. (2) Metode pembelajaran matematika berbasis saintifik dengan menggunakan mind maps efektif jika ditinjau dari self-efficacy siswa (3) Terdapat perbedaan yang signifikan setelah diterapkannya metode pembelajaran matematika berbasis saintifik dengan menggunakan cornell notes method dan mind maps ditinjau dari selfefficacy siswa, dimana metode pembelajaran matematika berbasis Saintifik dengan menggunakan mind maps lebih efektif jika ditinjau dari self-efficacy siswa.

Secara umum kita ketahui banyak faktor yang mempengaruhi hasil belajar siswa dalam suatu proses pembelajaran diantaranya adalah pemilihan metode pembelajaran yang digunakan. Ketika seorang guru ingin meningkatkan prestasi dan komunikasi matematis siswa maka metode santifik disintesiskan dengan linear note taking style (Cornell Notes) lebih cocok digunakan. Sedangkan metode saintifik yang disintesiskan dengan non linear note taking style lebih cocok digunakan untuk mengembangkan self-efficacy siswa. Agar pembelajaran dapat berjalan lancar ketika menggunakan kedua metode tersebut, sebaiknya guru di awal pertemuan mengajarkan cara membuat catatan dengan kedua style mencatat tersebut terlebih dahulu.

Guru dapat menggunakan metode pembelajaran matematika berbasis saintifik yang disintesiskan dengan linear note taking style dan non linear note taking style sesuai dengan

kebutuhan atau aspek apa yang ingin ditingkatkan. Jika yang ingin ditingkatkan adalah selfefficacy siswa maka dapat menggunakan metode saintifk yang disintesiskan dengan mind maps. Guru dapat mensintesiskan cornell notes method dan mind maps pada metode pembelajaran yang lain selain saintifik, misalnya pada metode problem solving maupun problem possing.

Untuk penelitian selanjutnya, agar siswa tidak bosan dengan gaya mencatat cornell notes method ada baiknya untuk memberikan reward bagi siswa yang mampu membuat catatan yang bagus sehingga dapat memacu teman-teman kelas yang lain untuk lebih aktif lagi sehingga tidak menimbulkan kebosanan selama pembelajaran berlangsung

\section{Refference}

Bandura, A. (1997). Self-efficacy in Changing Societies. New York: Cambridge University Press

Boch, F., \& Piolat, A. (2005). Note Taking and Learning : A Summary of Research. The WAC Journal.16(5), $101-111$

Burns, T., \& Sanfield, S. (2004). Teaching, Learning, and Study Skill: A Guide fir Tutors. London : Sage Publication Company

Buzan, T. (2006). The Buzan Study Skills Handbook: The Shortcut to Succes In Your Studies With Mind maps, Speed Reading, and Winning Memory Techniques. English: BBC Lifestyle

Cohen, L., Manion, L., \& Morrison, K. (2007). Research Method in Education. London: Routledge

Greany, T., \& Rood, J. (2003). Creating a Learning to Learn School. Stafford: Network Educational Press

Johnson, B. \& Christenen, L. (2012). Educational Research: Quantitative, Qualitative, and Mixed Approaches (4thed). Thousand Oaks, CA: SAGE Publication Inc. 
Kementrian Pendidikan dan Kebudayaan. (2013) Salinan Lampiran Permendikbud no 65 Tahun 2013. Kemendikbud

Kementrian Pendidikan dan Kebudayaan. (2013) Salinan Lampiran Permendikbud no 81a Tahun 2013. Kemendikbud

Kiewra, K.A. (2002). How Classroom Teachers Can Help Students Learn and Teach Them How to Learn. Theory into Practice collaborating with JSTOR, 41(2), 71 - 80.

Kaivola, T., \& Lokki, H. (2010). Using Concept Maps As A Note Taking Tool In Computer Science. Helsinski : University Of Helsinki

Liu, X \& Koirala, H. (2009). The Effect of Mathematics Self-Efficacy on Mathematics Achievement of High School Students. Paper North east Educational research Association Annual Confrence 22 Oktober 2009

Maddux, J.E. (1995). Self-efficacy, Adaptation and Adjusment. New York: Plenum Press

Mahmudi, A. (2009). Komunikasi dalam pembelajaran matematika. Journal MIPA UNHALU. 8 (1), $1-10$.

Makany, T., Kemp, J. \& Dror, I. E. (2009). Optimising the use of note-taking as an external cognitive aid for increasing learning. British Journal of Educational Technology, 40(4), 619-635

Marsigit. (Oktober 2015). Pendekatan Saintifik Dan Implementasinya Dalam Kurikulum 2013. Makalah disajikan dalam Seminar Workshop Implementasi Pendekatan Saintifik dan Pelaksanaan Kurikulum 2013 di ruang rapat lantai 2 LPPMP UNY

Taat, M.S., \& De Rozario, G. (2014). The influence Of Academic Attitude and Self-efficacyTowards Students Achievement In Private Higher Learning Institution Malaysia. International Journal of Arts and Commerce, 3 (6), 41 - 50

NCTM. (2000). Principles and standar for school mathematics. Reston, VA: The National Council of Theachers of Mathematics, Inc.

Nitko, A.J., \& Brookhart, S.M. (2011). Educational Assesment of Students. Boston, MA: Pearson Education

Pajares, F., \& Miller, D.M. (1997). Mathematics self-efficacy and mathematical Problem solving: implications of using different form assessment. The Journal of Experimental Education, 65 (3), $213-228$

Pajares, F \& Urdan, T. (2002). Academic Motivation of Adolescents. Greenwich, CT: Information Age Publishing.

Pauk, W., \& Owens, R.J. (2011). How To Study In College Tenth Edition. Ottawa: Wadsworth Cengange Learning ltd.

Santrock, J.W. (2011). Educational psychology (5thed). New York, NY: McGraw Hill Companies

Schneider, E., \& Peschek, W. (2002). Computer algebra systems (cas) and mathematical communication. The International Journal of Computer. 9(3), 231-238.

Ahmad, S., \& Husain, A. (2012). Relationship Of Academic SE to Self Regulated Learning, SI, test Anxiety and Academic Achivements. International Journal Of Education. 4 (1), 12 - 25

Stiggins, R. \& Chappuis, J. (2012). An Introduction to Student-Involved Assesment for Learning (6 ${ }^{\text {thed }}$ ). Boston, MA: Perason Education

Sumantri, Jujun S. (1994). Filsafat Ilmu. Jakarta : Sinar Harapan

Tsai-Fu. (2009). EFL College Freshman Note-Taking Training for Reading Comprehension. The Journal of Human Resource and Adult Learning. 5(2), 12-16 